\title{
Are all incapacitated people confined in a hospital, care home or their own home deprived of liberty?
}

\author{
Anselm Eldergill 1,2,3,4
}

Published online: 7 January 2019

(C) The Author(s) 2018

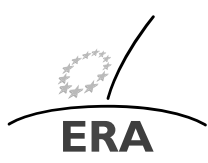

EUROPÄISCHE RECHTSAKADEMIE ACADEMY OF EUROPEAN LAW ACADEMIE DE DROIT EUROPEEN ACCADEMIA DI DIRITTO EUROPEO
TRIER - TREVES - TREVIRI

\begin{abstract}
In Stanev, the European Court of Human Rights was able to decide the application without determining whether 'any placement of a legally incapacitated person in a social care institution constitutes a deprivation of liberty'. Answering this question necessitates distinguishing carefully between loss of autonomy and loss of liberty. Determining the level of restraint in a particular situation involves establishing what the individual can do and wishes to do ('wills') but for any interference with their freedom to do it. It is a 'but-for test'. It is also critical to understand that the presence or absence of objections are relevant to the objective condition, not just the subjective condition.
\end{abstract}

Keywords European Convention on Human Rights · Incapacitated persons · Deprivation of liberty $\cdot$ Hospitals · Care homes · Autonomy $\cdot$ Liberty $\cdot$ Capacity

For the purposes of Article 5 of the European Convention on Human Rights, two conditions must both be met for a deprivation of liberty to exist: an objective condition and a subjective condition.

The objective condition is that the individual has been confined in a restricted space (such as a hospital, social care home or their own home) for a not negligible

\footnotetext{
A. Eldergill

medicolegal@email.com

1 Judge in the Court of Protection, London, UK

2 Solicitor; Honorary Professor of Mental Capacity Law, University College London, London, UK

3 Honorary Professor of Mental Health Law, Northumbria University, Newcastle-upon-Tyne, UK

4 Member of the United Nations Expert Committee on Capacity and Access to Justice, Geneva, Switzerland
} 
length of time. ${ }^{1}$ The distinction between a deprivation of liberty and a restriction of liberty is one of degree or intensity, not one of nature or substance. ${ }^{2}$ The starting-point is the concrete situation of the individual concerned and account must be taken of a whole range of factors such as the type, duration, effects and manner of implementation of the measures in question. In many court judgments the fact that the person 'is under continuous supervision and control and is not free to leave' has been decisive. ${ }^{3}$

It could be said that all incapacitated older people receiving institutional care for severe dementia (and, indeed, all younger people with similarly disabling conditions) are confined in this sense. They are under the continuous supervision and control of staff and would be prevented from leaving if they tried to leave. Are all of them deprived of their liberty and entitled to the Article 5 safeguards?

The subjective condition is that the individual 'has not validly consented to the confinement in question'. ${ }^{4}$ The natural meaning of the term 'valid consent' is that the relevant person has legal capacity to consent to care arrangements which objectively constitute a confinement and does consent. That implies that everyone with a significant dementia, learning disability or mental illness who lacks capacity to consent to what amounts to a confinement is deprived of their liberty. Because, by definition, they cannot validly consent to being confined is it therefore the case for them that only the objective condition is relevant?

These important questions were raised but not answered in Stanev. ${ }^{5}$ In that case the court was able to decide the application without needing 'to determine whether, in general terms, any placement of a legally incapacitated person in a social care institution constitutes a 'deprivation of liberty' within the meaning of Article $5 \S 1$ '.

According to the jurisprudence, the answer turns partly on the significance one attaches to whether a person who lacks legal capacity to 'validly consent' to care arrangements that involve confinement, lack of freedom to leave and/or continuous supervision and control is able to 'understand their situation' and agrees with or at least does not object to the arrangements.

There is a tension here-and possibly a trade-off_-between not imposing formal legal procedures and orders on incapacitated people who can express their wishes and feelings, and are content with their care arrangements, and ensuring that the liberty of

\footnotetext{
${ }^{1}$ Given the purpose and terms of the Convention, it is of course necessary that a confinement $\mathrm{s}$ is imputable to the state.

${ }^{2}$ Ashingdane $v$ the United Kingdom, judgment of 28 May 1985, Series A no. 93, p. 19, §41.

${ }^{3}$ This test would be better phrased if the requirement was that the person 'is under continuous supervision and control and is unable to leave'. The current formulation is appropriate for people without impaired capacity because it is based on the premise that a person who is free to leave and objects to being under continuous supervision and control can promptly bring this state of affairs to an end by leaving. It is less satisfactory if the person does not realise they can leave or that they have a choice. 'Unable to leave' includes both those who are prevented from leaving and those who are unable to leave because of lack of capacity.

${ }^{4}$ Shtukaturov v Russia, no. 44009/05, 27 March 2008, 54 EHRR 962, §106. See also Storck v Germany, no. 61603/00, 16 June 2005, ECHR 2005-V, 43 EHRR 96, [2005] ECHR 406, §74; Stanev v Bulgaria [GC], no. 36760/06, 17 January 2012, [2012] ECHR 46, §117; mutatis mutandis, HM v Switzerland, HM $v$ Switzerland, no. 39187/98, 26 February 2002, ECHR 2002-II, [2002] ECHR 157, (2002) 38 EHRR 314, $\S 46$.

${ }^{5}$ Stanev v Bulgaria [GC], no. 36760/06, 17 January 2012, [2012] ECHR 46.
} 
all incapacitated persons who are not permitted to leave their place of residence, and whose movements are supervised and controlled by others, is protected by the law.

English and Welsh law has gone round in circles in this respect. Since 1890 it has moved from an era where all psychiatric hospital patients had to be detained under formal legal orders to the position where people with capacity could consent to voluntary admission, ${ }^{6}$ to the position where those incapable of consenting to voluntary admission could be admitted to hospital for psychiatric treatment without a formal legal order, in the same way as patients needing treatment for physical ailments, ${ }^{7}$ and back now to the position that capacity and consent are required in all cases where the patient would not be allowed to leave should they attempt to leave. ${ }^{8}$

In Storck, ${ }^{9}$ the court stated that even if the applicant had lacked capacity to consent to her stay in the clinic 'she could ... not be considered as having validly agreed to [it]', ${ }^{10}$ thereby raising the possibility that whether a deprivation exists could turn on subjective 'valid agreement' rather than 'valid legal consent'. In Shtukaturov, ${ }^{11}$ the court emphasised that the fact that a person lacks legal capacity does not dispense with the second condition by rendering irrelevant the question of whether or not they 'object' to their confinement and regime. ${ }^{12}$ The court was unable to accept the government's view that the applicant had 'agreed' to his continued stay in the hospital. ${ }^{13}$ In $D D v$ Lithuania, ${ }^{14}$ the fact that an incapacitated person 'objected' to their stay, and 'subjectively perceived' their compulsory admission as a deprivation of liberty, were critical factors in finding that a deprivation of liberty existed. Likewise, in $\mathrm{Mi}$ hailovs ${ }^{15}$ where the applicant had resided at two locations, the court found that he 'subjectively perceived his compulsory admission [to the first location] ... as a deprivation of liberty' and never regarded his 'admission to the institution as consensual', 'objecting to it' during his stay there. ${ }^{16}$ However, he had the 'tacitly agreed' to his stay at the second location 'implicitly confirming that he did not have any objections'.

'Context is everything' is a common saying and the context is significant here. Historically, the subjective condition, as has been noted, is that no valid consent has been given to a confinement which meets the objective condition. A problem faced by the court in the most recent three of these cases was that as a matter of domestic law the incapacitated person's guardian had validly consented to the placement on their

\footnotetext{
${ }^{6}$ See the Mental Treatment Act 1930.

${ }^{7}$ See Report of the Royal Commission on the Law relating to Mental Illness and Mental Deficiency 1954-57, Chairman-Lord Percy, Cmnd. 169 (1957), commonly referred to as 'the Percy Report', and the Mental Health Acts 1959 and 1983.

${ }^{8}$ See the Mental Capacity Act 2005 and $P v$ Cheshire West and Chester Council and $P$ and $Q v$ Surrey County Council [2014] UKSC 19, commonly referred to as the 'Cheshire West case'.

${ }^{9}$ Storck v Germany, no. 61603/00, 16 June 2005, ECHR 2005-V, 43 EHRR 96, [2005] ECHR 406.

${ }^{10}$ Storck v Germany, no. 61603/00, 16 June 2005, ECHR 2005-V, 43 EHRR 96, [2005] ECHR 406, §76.

${ }^{11}$ Shtukaturov v Russia, no. 44009/05, 27 March 2008, 54 EHRR 962.

${ }^{12}$ Shtukaturov v Russia, no. 44009/05, 27 March 2008, 54 EHRR 962, §107-09.

${ }^{13}$ Shtukaturov v Russia, no. 44009/05, 27 March 2008, 54 EHRR 962, §109.

${ }^{14}$ DD v Lithuania, no. 13469/06, 14 February 2012, [2012] ECHR 254.

${ }^{15}$ Mihailovs v Latvia, no. 35939/10, 22 January 2013, [2013] ECHR 65.

${ }^{16}$ Mihailovs v Latvia, no. 35939/10, 22 January 2013, [2013] ECHR 65, §134.
} 
behalf. The underlying issue was this: Where a guardian is authorised under domestic law to consent to an incapacitated person's placement in a care home or hospital, and consents to a regime of continuous supervision and control there, does this mean that there can be no deprivation of liberty?

Several European countries provide by legislation for a guardian to authorise or consent to a residential placement on behalf of an incapacitated person. As concerns this fact, the court accepts that there are situations where the wishes of a person 'with impaired mental faculties may validly be replaced by those of another person acting in the context of a protective measure, and that it is sometimes difficult to ascertain the true wishes or preferences of the person concerned' ${ }^{17}$

The effect of the decisions in DD, Mihailovs and Shtukaturov is that, notwithstanding a guardian's valid legal consent to a confinement under national law, it is still necessary to consider whether the person affected objects or agrees to their confinement and regime. If the person 'objects' to their stay, does not 'validly agree' to it or 'subjectively perceives their compulsory admission as a deprivation of liberty', which clearly requires some understanding of their situation, the arrangement is likely to constitute a deprivation of liberty. Consequently, the person affected must have the benefit of the protections afforded by Article 5, and in particular the right of appeal to a court imposed by Article 5(4). ${ }^{18}$ This is a valuable additional safeguard. The practical significance is that European countries may continue to operate guardianship schemes but a legally incapacitated person confined in pursuance of a guardian's decision must have access to the courts if s/he objects to or does not agree with a decision by their guardian to authorise confinement.

For the record, that approach is virtually identical in substance to the 'standard authorisation' scheme currently in force in England and Wales. Under this scheme, the state must ensure that incapacitated persons deprived of their liberty pursuant to an administrative scheme operated by local authorities have access to a court if they object to their confinement.

The limitation of such a legal framework is that some people are unable to express their wishes and feelings or are unable to object to residential arrangements made for them. The simple answer to this concern is that is why a guardian has been appointed to protect their interests. Provided care is taken to appoint a suitable guardian, and there are mechanisms in place for challenging the decisions of guardians and removing unsuitable guardians, such an approach complies with Article 5.

The earlier case of Storck suggests that an approach based on whether the relevant person agrees or objects to being confined could also be appropriate where there is no authorised guardian, mentor, attorney or the like to give a vicarious consent and to take personal welfare decisions which the person lacks legal capacity to make. However, the legal landscape and ramifications are somewhat different in this situation.

Where no guardian or authorised person has been appointed, there are essentially two options. The strict view is that all objective confinements are a deprivation of liberty if the relevant person is too incapacitated to legally consent to the arrangement.

\footnotetext{
${ }^{17}$ Stanev v Bulgaria [GC], no. 36760/06, 17 January 2012, [2012] ECHR 46, §130; Mihailovs v Latvia, no. 35939/10, 22 January 2013, [2013] ECHR 65, §134.
}

${ }^{18}$ Shtukaturov v Russia, no. 44009/05, 27 March 2008, 54 EHRR 962, §109. 
The alternative view is that professionals and family members may make appropriate care arrangements and a deprivation of liberty only exists to the extent that the person affected objects to or does not 'validly agree' with arrangements that involve an objective confinement. However, while the decisions in DD, Mihailovs and Shtukaturov can be seen as ensuring that a guardian's powers to consent to care arrangements are subject to safeguards, no such interpretation is possible here. Holding that a deprivation of liberty only exists if the person objects to being confined is a dilution of the principle that all confinements are a deprivation of liberty and give rise to Article 5 rights unless the person is able to give a valid legal consent to what is done to and for them.

This is in essence why the United Kingdom Supreme Court in Cheshire West rejected the approach in $D D$, Mihailovs and Shtukaturov, holding instead that whether a person understands their situation, objects to not being free to leave, or to being under continuous supervision and control, is irrelevant:

'35 [...] A mentally disordered person who has been kept in a cupboard under the stairs (a not uncommon occurrence in days gone by) may not appreciate that there is any alternative way to live, but he has still been deprived of his liberty.' 19

'50 [...] we should indicate the test and those factors which are not relevant

[...] [It is suggested] the person's compliance or lack of objection is not relevant; the relative normality of the placement (whatever the comparison made) is not relevant; ... For the reasons given above, I agree with that approach.' ${ }^{20}$

The use of the word 'not relevant' is unfortunate because at the very least whether the person objects is relevant to the objective condition and to establishing whether they are under continuous supervision or control and are not free to leave.

The obvious advantage of this approach is that there are many people whose mental impairment is so profound that they can neither understand nor therefore object to any placement, supervision and control. It avoids therefore the legal consequence that such people are not deprived of their liberty simply because of the absence of any objection to objective confinement. In such cases, if those who have control over the premises intend that the person should not be permitted to leave, and have the ability to prevent them doing so, that is a deprivation of liberty.

The disadvantage of the approach for some is the consequence that many hundreds of thousands of people living in their own homes, with foster parents or in supported accommodation across Europe are deprived of their liberty for Article 5 purposes even though their wishes and feelings, indicate that they are content with their situation and the need to actually confine them is purely or largely hypothetical.

One of the Cheshire West cases involved a young woman referred to as MIG. MIG was aged 19 and had 'a mental age of two-and-a-half'. She had problems with her sight, for which she wore glasses, and with her hearing, for which she wore a hearing

\footnotetext{
${ }^{19} P v$ Cheshire West and Chester Council and $P$ and $Q v$ Surrey County Council [2014] UKSC 19, per Lady Hale at paras. 35, 50, 51.

${ }^{20} P$ v Cheshire West and Chester Council and $P$ and $Q v$ Surrey County Council [2014] UKSC 19, per Lady Hale at para. 50.
} 
aid. She communicated with difficulty, 'indeed hardly at all in sentences' and had 'limited understanding'. She lived 'largely in her own world and spent 'much of her time listening to music on her iPod'. She lived in 'an excellent foster home' and was devoted to her foster mother. She had her own bedroom; the door was never locked; she had never attempted to leave the home on her own; and had never showed a wish to do so. Her foster mother provided intensive support in most areas of daily living. She was transported to and from further education each term-time day and her foster mother took her out on trips and holidays. She was not in receipt of medication but did need help crossing the road because she was unaware of danger.

The Supreme Court held that she was deprived of her liberty because 'were she to attempt to leave' her foster mother would restrain her. According to Lady Hale:

'53 ... her foster mother and others responsible for her care exercised complete control over every aspect of her life. She too would not be allowed out without supervision, or to see anyone whom they did not wish her to see, or to do things which they did not wish her to do.

54 If the acid test is whether a person is under the complete supervision and control of those caring for her and is not free to leave the place where she lives, then the truth is that [she is] being deprived of [her] liberty.'

It is clear, however, that Lady Hale herself had some reservations about this conclusion:

' 55 Several objections may be raised to the conclusion that both MIG and MEG [MIG's sister] are being deprived of their liberty ... they are both content with their placements and have shown no desire to leave. If the "tacit acceptance" of the applicant was relevant in Mihailovs, why should the same tacit acceptance of MIG and MEG not be relevant too? I have found this the most difficult aspect of the case. But Mihailovs was different because he had a level of de facto understanding which had enabled him to express his objections to his first placement. The Strasbourg court accepts that there are some people who are not capable of expressing a view either way and this is probably the case with both MIG and MEG. As HL 40 EHRR 761 shows, compliance is not enough. Another possible distinction is that, if either of them indicated that they wanted to leave, the evidence was that the local authority would look for another placement: in other words, they were at least free to express a desire to leave.'

A possible objection to that passage would be that MIG's contentment and devotion to her mother were telling expressions of her wishes and feelings and evidence that she had no objection to express, by words or behaviour.

As with the setting of all human rights standards, there was a public policy element to the court's decision. Notwithstanding some reservations, Lady Hale considered that:

Policy

'57 Because of the extreme vulnerability of people like P, MIG and MEG, I believe that we should err on the side of caution in deciding what constitutes a 
deprivation of liberty in their case. They need a periodic independent check on whether the arrangements made for them are in their best interests [...]'

In reaching her view, Lady Hale and the Supreme Court relied heavily on the judgment of the European Court of Human Rights in HL v United Kingdom 40 EHRR 761 (commonly referred to in the UK as 'the Bournewood Case'). In the Bournewood case, a deprivation of liberty was found to exist even though HL was compliant, expressed no objection and had never attempted to leave the hospital where he was an in-patient.

While that is certainly true, HL's circumstances were very different to those of MIG. He had suffered from autism since birth, was unable to speak and his level of understanding was limited. He was frequently agitated and had a history of selfharming behaviour. He lacked the capacity to consent or object to medical treatment. At the relevant time he had been living with his carers for over three years, after spending 30 years as an in-patient at Bournewood Hospital. On 22 July 1997, following an incident of violent behaviour and self-harm at his day-care centre, he was sedated and taken to hospital and subsequently to the Intensive Behavioural Unit, in the latter case supported by two persons. He was unable to express dissent to his removal to hospital and never indicated that he wished to leave. He fully complied with his treatment and therefore was not detained under mental health legislation (the Mental Health Act 1983). According to Lord Steyn in the House of Lords, 'hospital staff regularly sedated him. That ensured that he remained tractable.' His psychiatrist vetoed visits by his carers in order to ensure that he did not try to leave with them. Health care professionals exercised effective power over him and if he had tried to leave his psychiatrist would immediately have taken steps to detain him under the Mental Health Act 1983. She told his carers that he would be released only when she, and other health care professionals, deemed it appropriate.

Having considered these facts, the European Court of Human Rights did not consider that the fact that HL 'was compliant and never attempted, or expressed the wish, to leave' was determinative. This was because it was 'not disputed that [he] is legally incapable of consenting to, or disagreeing with, the proposed action' [para. 90]. The 'key factor' in his case was that 'the health care professionals treating and managing [him] exercised complete and effective control over his care and movements from 22 July 1997, when he presented acute behavioural problems, to 29 October 1997, when he was [eventually] compulsorily detained [under the Mental Health Act 1983]'. ${ }^{21}$

The context is again significant. At the time of HL's case many people in England and Wales were effectively detained in psychiatric units on an informal basis. The twin justifications were that the Mental Health Act 1983 expressly provided for informal admission and the common law authorised giving treatment to people who could not consent to it provided such treatment was considered to be in their best interests. People with learning disabilities who were unable to understand their situation or to object to treatment were often detained and given treatment informally. ${ }^{22}$

\footnotetext{
${ }^{21}$ HL v United Kingdom, no. 45508/99, 5 October 2004, ECHR 2004-IX, (2004) 40 EHRR 761, §91.

${ }^{22}$ The author practised mental health law as a solicitor for 25 years before becoming a judge. As a Mental Health Act Commissioner, he visited the Royal Earlswood Hospital for people with a learning disability
} 
Similarly, legally incapacitated people with a mental illness such as schizophrenia were often 'de facto detained' on psychiatric wards. What this term meant was that in reality they were not free to leave-they knew that, their psychiatrists knew that, the nurses knew that. Because everyone knew that the person would be prevented from leaving and detained under the Mental Health Act if they made for the door, the patient did not attempt to leave and no application to detain them under the Act was made. In all of these cases the person was effectively deprived of their liberty but without any of the rights of appeal of a detained patient because no order authorising their deprivation of liberty existed. Nor, given the absence of a formal order detaining them, was the person under the protection of the Mental Health Act Commission. ${ }^{23}$

The HL decision stamped out these abuses of the informal admission process by requiring the United Kingdom to ensure that a proper legal procedure is in place, with proper safeguards and rights of appeal, whenever an incapacitated person is deprived of their liberty in circumstances similar to those described.

The decisions in Cheshire West and HL are at one in that both literally and strictly apply the subjective condition that a confinement constitutes a deprivation of liberty if the relevant person has not validly consented to it. It does not matter that they are compliant, because compliance is not the same as consent and many incapacitated people are unable to object or are too timid or over-awed to object.

That said, the reality of MIG's situation and that of HL could hardly be more different and it is possible to distinguish them. The objective and subjective conditions for a deprivation of liberty overlap so that the presence or absence of coercion, a person's wishes and feelings, the existence of objections, and the absence of objections from someone capable of objecting, are always relevant to the objective condition, not just the subjective condition. ${ }^{24}$

The 'concrete situation' in HL's case was that he met the statutory criteria for detention under mental health legislation, restraint was used, he was placed in the Intensive Behavioural Unit, he was regularly sedated so as to keep him tractable, and

in the mid-1990s. Although the hospital had over 300 in-patients and three secure units, only four of the patients were detained under mental health legislation. The rest were there 'informally'.

${ }^{23}$ The situation in 1997 prior to the Bournewood case is summarised in Eldergill [3], pp. 4-5: 'The vast majority of people who receive in-patient psychiatric treatment are treated without resort to compulsory powers and they are known as "informal patients." Although informal patients are sometimes still referred to as "voluntary patients," the terms are not synonymous. A significant number of informal patients lack sufficient capacity to consent to their admission, are mentally incapable of organising their own discharge, or remain in hospital informally only because compulsory powers will be invoked if they refuse treatment or attempt to leave. Informal admission may be particularly disadvantageous for people who are mentally incapacitated in that the necessity for their being in hospital, and the treatment and care which they receive there, are not susceptible to periodic external review by the Mental Health Act Commission or a mental health review tribunal. Whilst the use of compulsory powers deprives the person affected of certain legal rights, it also confers other rights in substitution. Since these are framed as duties exercisable by third parties on the patient's behalf, they may in practice more than compensate the patient for the loss of rights the existence of which he is unaware or, if aware of them, incapable of exercising. Although most formal patients understandably wish to be informal, there are nevertheless a number of patients who are incapable of understanding or exercising the legal rights which constitute the practical benefits of being an informal patient.'

${ }^{24} P v$ Cheshire West and Chester Council and $P$ and $Q v$ Surrey County Council [2014] UKSC 19, per Lady Hale at para. 38. 
he was not allowed to see his carers 'in order to ensure that he did not try to leave with them'. On any reasonable view that satisfies the objective condition.

In MIG's case, she was not detainable under mental health legislation, was living in an ordinary home, was devoted to her foster mother, was content, had never attempted to leave home and had never showed a wish to do so. Introducing the hypothetical future possibility that if ever she were to attempt to leave she would be prevented from doing so arguably involves considering not her 'concrete situation' but an artificial situation. One is no longer focusing on and taking 'account of the type, duration, effects and manner of implementation' of the measures in question but determining whether a deprivation of liberty presently exists by reference to a future conditional event that has never previously occurred, is unlikely ever to occur and has no impact on the person's present circumstances.

A second distinction is the degree of supervision and control to which HL and MIG were subject. Where an incapacitated person is unable to leave the place where they are being cared for because they lack capacity to leave, the critical issue is not, since they are unable to leave, whether hypothetically they would be prevented from leaving but the intensity of the regime and how it impacts on their liberty. What measures are in force and what is their "manner of implementation, duration and effect'? Is the regime one of continuous control and supervision or one more akin to continuous care and supervision? HL was compliant and did not try to leave for want of understanding but in addition his concrete situation was that he was subject to continuous supervision and control in the form of sedation, physical restraint and lack of contact with his carers. The duration and intensity of these measures constituted a deprivation of liberty in the absence of valid consent, which he was unable to give. By contrast, MIG was not subject to intensive control of this kind, quite the opposite and, given that the difference between a deprivation and a restriction of liberty is one of degree or intensity, on this ground also it could be contended that the threshold for a deprivation of liberty was not crossed in her case.

A third distinction, if agreement or tacit agreement rather than absence of objection is a factor relevant to the subjective condition, would that MIG's wishes and feelings could be implied from her devotion to her foster mother and the absence of any need for restraint or sedating medication. She was content and had no objection to express, by words or behaviour. In HL's case no tacit agreement to the regime could be inferred given that he was physically restrained, sedated and denied contact with his carers because of the possibility he might wish to leave with them.

It is obvious therefore that these legal problems concerning what constitutes a deprivation of liberty are profoundly difficult. On reading the case law, part of the difficulty may arise from the fact that relatively little attention has been paid to defining and distinguishing between liberty and autonomy. In order to determine what is a deprivation of liberty it is necessary to define the term 'liberty', and doing this and avoiding confusion necessitates carefully distinguishing between the concepts of 'liberty' and 'autonomy'.

Liberty is in fact not an end in itself-autonomy is the end-and liberty is cherished because it is one of the two necessary preconditions of autonomy. The other is capacity.

The promotion of autonomy is a key objective of European society in general and of the European Convention on Human Rights in particular. The reason is obvious. 
Society is made up of individuals and each individual has distinctive feelings, personal goals, traits, habits and experiences. Variety is the essence of the human race and not a passing condition. Because this is so, most individuals wish to determine and develop their own interests and course in life. They wish to be autonomous, that is self-directing and self-governing, and it is for this reason that people place such weight on their liberty and right to choose.

People experiencing mental illness may be held not to have the capacity for autonomous action and in consequence their liberty may be curtailed, but the desire for autonomy is of equal fundamental importance to all citizens who have wishes and preferences about where and how to live.

Although the legal position of citizens is underpinned by these concepts of autonomy, capacity and liberty, what do the terms actually mean and what is their relationship? While acknowledging that some words have no meaning at all, ${ }^{25}$ Locke recognised that to require that all people should use words in the same sense and have clear ideas on them would be to expect they should talk of nothing but what they had clear ideas on, which was absurd. ${ }^{26}$ Words must be used in order to formulate theories $^{27}$ and their precise meaning may only emerge gradually as the ideas in them are submitted to enquiry. ${ }^{28}$ However, the way in which terms are defined and used is significant and, where possible, the logic of terminology should reinforce the conceptual framework. ${ }^{29}$

Exploring what we mean in everyday life when we say that an individual is able to do something provides a useful reference point when considering what in law we mean, or should mean, when we say that a person is or is not able to do a particular act. This is a question of fundamental importance because how much autonomy each of us is permitted turns on the answer.

A good starting-point is the distinction between ability and capability: what one is able to do and what one is capable of doing.

Ability is what we are actually able to do: we are either able to do something or not. For example, I am able to speak English.

The concept of legal 'capacity' closely corresponds to this everyday use of the word 'ability'. Consequently, English and Welsh legislation refers to a person who lacks capacity as being 'unable' to make the decision in question. If a person is 'able' to make a will then it is up to them whether or not to make one and, if they choose to,

\footnotetext{
${ }^{25}$ For example, the names of simple ideas such as colours and tastes cannot be defined: 'This is clear, for if a thing has no parts you cannot enumerate its parts. Neglect of this simple truth has led to much confusion, persons trying to define everything, and thus giving rise to much wrangling and absurdity': Bodkin [2], p. 160.

${ }^{26}$ Locke [5], p. 477. 'When a word stands for a very complex idea it is not easy for men to form and retain that idea so exactly that it will not vary now and then. Hence such words have seldom in two men the same significance, and even the meaning changes from day to day. Furthermore, if men have not standards whereby to adjust the signification of these words, then the significance becomes doubtful and, the rule of propriety of language itself being nowhere established, it is often a matter of dispute whether this meaning or that is more correct, according to usage': Ibid., pp. 478-479.

${ }^{27}$ Popper [7].

${ }^{28}$ Roth [8], p. 12.

${ }^{29}$ World Health Organisation [10], pp. 32-33.
} 
whom to provide for. Similarly, if a person is 'able' to make a decision about whether to have treatment it is up to them whether to have or refuse it.

When a court finds that a particular person is 'unable' to do something it is their current ability which determines this. The individual may be capable of improving their legal capacity over time but their present capacity is determined by whether they are able to do the particular thing at present.

Why then is the term 'legal capacity' used in preference to 'legal ability'? By convention the word 'capacity' has been preferred to indicate a passive or receptive power - in particular, an aptitude for assimilating and retaining information or knowledge — and 'ability' has been used to denote an active power. ${ }^{30}$ A person has the intellectual 'capacity' to understand or apprehend ('take in') what they see, read or hear but the 'ability' to perform an action such as walking, running or talking.

The original underlying idea was that a brain has a mental capacity to receive and absorb relevant information analogous to the capacity of a container or a sponge to hold a liquid. Whether a person can be bothered to fill the container with relevant information or prefers to act rashly without it is neither here nor there. What is important is that they have this 'capacity'. If because of a learning disability the container is not capacious enough to be able to hold and retain all of the relevant information, or it is damaged in a way that prevents information from being retained and weighed as a result of mental illness, then the person may be said to lack capacity-legal ability - to make a decision or perform an act. ${ }^{31}$

However, in everyday conversation, we might just as easily say without being contradicted that the person is 'able' to understand what they read or what is said to them. Equally, we may say that although they are 'able' to understand the information given to them and are 'able' to make a decision they cannot be bothered to do either.

In addition to present abilities, most people are also capable of other things. A capability may be an ability which the person already has to some extent but can be improved or developed (capable of 'more or better') or something the person is presently unable to do at all.

Someone living in a non-English speaking country may not be able to speak English but be capable of doing so. Most people are capable of learning to read and write but many are unable to do so for want of past opportunity or need.

However, I am neither able to run 100 metres in under ten seconds nor capable of doing so. I lack the necessary physique and talent. This is a limitation of nature. It is how the world is and I am.

When therefore we consider a person's abilities and capabilities, all activities can be placed in one of three groups: there are activities which the individual is presently able to do (speaking English in my case); activities which the individual is presently unable to do, or unable to do at a certain level of proficiency, but is capable of (speaking Japanese, on a spectrum from poorly to fluently); and activities which the individual is incapable of (running 100 metres in under ten seconds):

30 'Capacity,' says H. Taylor, 'is requisite to devise, and ability to execute, a great enterprise': Whitney [9].

${ }^{31}$ In recent times great emphasis is placed on the weight given to the information retained in the container. 
Capable of doing

(Presently unable but potentially able)
Able to do

(What presently we are able to

do)
Incapable of doing

(Not possible)

What we are able to do now and the things we are capable of are determined by our innate capabilities and individual development. Whether our capabilities become abilities depends on many factors such as our age, physical maturity, character, interests, environment, opportunities, resources, parental influence, education, culture, stimulation and encouragement. If I live in Japan I will probably be able to speak Japanese and if I live in France French. If I am brought up in one environment or culture, I will be taught or need to able to do certain things which are not passed on or required in another place.

In short, all of the physical, mental and environmental factors that impact on our lives go into the melting pot which is 'us' and determine what each of us is able to do, what we are capable of doing and what we are incapable of.

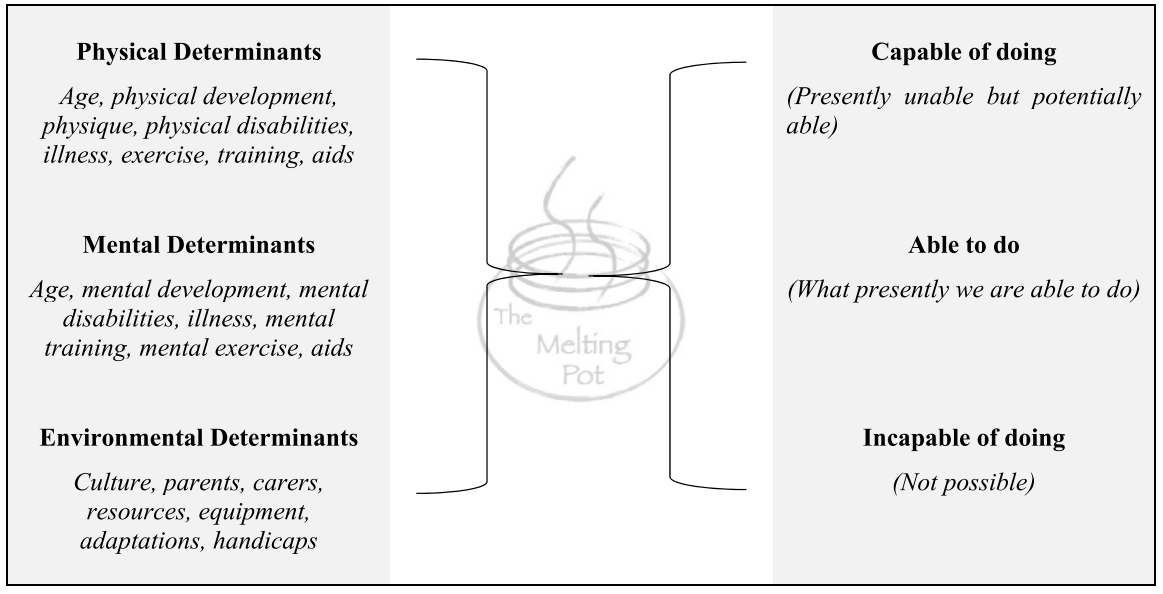

Used in this way, 'ability' focuses on the individual and the range of activities which they are able to perform without regard for whether the particular activities are presently available to the person to do.

It includes therefore activities which the individual is able to perform with the benefit of any assistive mental and physical aids they currently have. For example, a person with an artificial hip is able to walk; a person who has lost the use of their legs but has a wheelchair is able to mobilise; a person whose epilepsy is controlled by medication is able to drive; someone whose agoraphobia is controlled with treatment is able to work outdoors.

In some cases it may be easy to enhance a person's range of abilities. With an aid they may be able to do something which a few minutes ago they were only capable of. Providing a wheelchair to someone with a physical impairment may mean that they are no longer only capable of mobilising, they are able to do so. The extent to which 
the person is disabled by their physical impairment has been reduced. The particular activity no longer sits in their category of capabilities but in the category of abilities.

Physical and mental maturation, education, training, stimulation and encouragement may all have the like effect of extending the range of activities a person is able to perform, by turning capabilities into abilities. A person with a learning disability who is currently unable to understand what is necessary to make a will may soon be able to make one if given encouragement, education and support. Natural recovery, physiotherapy after an accident and restoring a person to health following a disabling illness may have the rehabilitative effect of restoring the range of activities a person is able to perform.

Why are these distinctions relevant to discussions about deprivation of liberty? In the first place, I cannot properly speak of being prevented by others from doing something I am incapable of doing. It would be nonsense for me to say that I am not free to run 100 metres in under ten seconds or that I am not at liberty to do so. Berlin refers to Helvetius making the same point: ' ... it is not lack of freedom not to fly like an eagle or swim like a whale'. ${ }^{32}$

Secondly, it is also true that I cannot properly speak of being coerced or prevented by others from doing something which I am capable of doing but am presently unable to do. No one can possibly restrain me from speaking (as opposed to seeking to learn) Japanese because I do not have this ability at present. Mere inability is not a lack of freedom.

A more relevant example of this second principle is again that of someone with a physical impairment who is unable to mobilise independently but capable of doing so with a wheelchair. If that person has no wheelchair they are not able to mobilise independently; and, because presently they are not able to mobilise independently, logically no one can interfere with their liberty to mobilise independently. ${ }^{33}$ The limiting factor in the individual's life does not arise from any external coercion or restraint on their freedom to act but from their own inability to do an act which they are capable of, in this case for want of an inexpensive aid.

Although some dictionaries define autonomy as 'freedom', this illustrates that freedom and autonomy are not synonymous. If a person in this situation acquires a wheelchair, they no longer rely on others to mobilise. They are now able to mobilise autonomously, that is independently. Their dependence on others is less and their ability to self-govern, to direct their own life, that much more. However, the person's autonomy has increased without there being any increase or decrease of coercion or liberty.

Autonomy requires not only freedom from coercion but also that one can act independently, which in turn depends on an ability to will an act and the ability to execute it. A dead person though not coerced has no autonomy. A free person who is unconscious has no ability to act autonomously. A free baby is entirely dependent on others to feed and clothe it and has little ability to act autonomously of others. At the other end of life, as the abilities of a free older person with dementia decrease they become

\footnotetext{
${ }^{32}$ Berlin [1], p. 122.

${ }^{33}$ It would be different of course if they had a wheelchair and it was then taken away from them in order to prevent them from mobilising.
} 
correspondingly more dependent on others to perform for them activities which previously they were able to execute autonomously.

Autonomy is more synonymous therefore with independence. Freedom is necessary but also the ability to do the act in question. Just as a country that gains independence is now self-governing and self-directing - it is able to act independently and free to act independently-so a person is autonomous to the extent that they are able and free to act independently.

It has already been noted that ability focuses on the individual and the range of activities which they are able to perform without regard to external circumstances and whether or not these activities are presently available to the person to do. For example, I am 'able to' swim but it may be that I cannot swim at this moment because no pool is available or I am prevented by someone from doing so.

What an individual 'can do' at any given moment therefore involves considering not only what they are 'able to do' but also their external world and, in particular, what is available for them to do and what they are permitted by others to do. What each of us 'can do' at any precise moment differs from what we could do if circumstances were different.

External circumstances may restrict our activities-what we 'can do' - in two ways: we may be subject to restraints or to constraints.

Taking the first of these two limiting factors, it may be that we cannot do something because we are restrained from doing it. In essence there are two kinds of restraint. The first kind I refer to as 'pre-existing restraints' because they have already been put in place by others and are now fixed features of our external world. The classic example is that of a prisoner. A prisoner's activities are controlled by others. At all times what he or she can do is limited by and subject to pre-existing restraints imposed by people in positions of authority who both claim and have the power to restrain the individual's activities as they deem fit. But for this continuing interference by others with their freedom they would not be in prison.

We refer to a comprehensive restraint of liberty of the kind endured by a prisoner or a patient detained under mental health legislation as a deprivation of liberty. In other situations, a person may be subject to pre-existing restraints of a lesser but still significant kind, for example parole conditions, conditions imposed on a patient discharged from a psychiatric hospital, bail conditions or an injunction which prevents a person from going to a particular place. We refer to such legal regimes as constituting a 'restriction of liberty' when they are not considered to be sufficiently intrusive or all-encompassing as to amount to a deprivation of liberty.

In the case of pre-existing restrictions, the restrictions to which the individual is now subject will either be a matter of law (in the case of a term of imprisonment) or recorded in the order itself (in the case of conditions imposed on a citizen living in the community). The approach with pre-existing restraints is therefore to note the powers which the order gives those in authority over the individual (for example, that the person be confined in prison and subject to prison rules), the legal conditions to which the person is subject (for example, they must live at a particular address and observe a curfew) and the acts which the person or a person in their position is prohibited from doing (for example, that they do not visit a particular locality). One is then in a position to ask whether the breadth and intensity of these restrictions are 
sufficiently intrusive and all-encompassing that they go further than merely restricting the person's liberty to live as they choose and effectively deprive the individual of their liberty. The subjective condition is usually irrelevant because the order is imposed on the individual and it is obvious that they do not consent to any authorised confinement. $^{34}$

Because pre-existing restraints are founded on a legal order and the confinement or restrictions continue in force until they expire or are terminated by a court, an individual's subjective awareness of whether they are confined or at liberty is not determinative. A prisoner is still a prisoner even when asleep and unaware of the fact that they are confined to a cell. When asleep I am not conscious that I am at liberty and when asleep a prisoner is not conscious that they are confined. However, I am at liberty and they are confined. The distinction lies not in subjective awareness when asleep but in objective reality, the objective reality being that what the prisoner can do if he or she wishes when awake is subject to external restraint by others whereas what I wish to do and can do when awake is not. Likewise, a prisoner who is in a coma is still deprived of their liberty. The order remains in force and but for the interference by another person with their freedom they would not be in prison.

The second kind of restraint arises when an individual not subject to any preexisting restraints - a notionally 'free' citizen not subject to legal sanctions such as MIG, HL or me-interacts with their external world. Another person may restrain them from doing an act. The individual armed with their abilities interacts with their external world and is prevented by someone from doing what they are able to do and can do but for the restraint. For example, reading, mobilising, communicating freely with others, self-harming, harming others, accessing the external world and its activities. As Hobbes put it, 'A free man is he that ... is not hindered to do what he hath the will to do'. 35

What we can do is not limited only by personal inability or by restraints on our liberty imposed by persons in our external world. The external world may restrict our activities in a second way because a person who is able to do an activity and is not restrained by anyone from doing it is also subject to constraints. Ability and an opportunity to exercise the ability must overlap.

Although our mental and physical abilities enable us to undertake many activities, some of them compound activities that require us to exercise and co-ordinate several abilities at once, our current circumstances do not enable all of them to be done at

\footnotetext{
${ }^{34}$ There is a 'grey area', however, in the case of probation-type orders that can only be imposed by a criminal court with the person's consent. It is sometimes argued that no valid consent has been given because their agreement was given under duress, a more Draconian sentence such as imprisonment being the likely alternative if they refused consent. On the other hand, if they have capacity to consent the fact that neither alternative is particularly attractive does not mean that their consent is not valid. It is similar to the position where a bank manager says, "You can agree to these terms for paying back the $£ 10,000$ overdraft or be taken to court". The fact that my preferred alternative, that I never pay the sum back, is not available as a choice does not mean that my consent to the bank's terms is invalid. Another grey area would be where a litigant gives an undertaking to the court and as a result avoids the imposition of an injunction.

${ }^{35}$ Berlin [1], p. 123; Hobbes [4], Ch. XXI. 'Hindrance' is a useful word in this context because it emphasises that the restraint may not always be as overt as being physically restrained, sedated or locked in a room. Some forms of restraint, such as duress and veiled threats of unpleasant consequences, may be less obvious but equally devastating in hindering us from doing what we are able to do and can do but for the restraint.
} 
this moment in time. Our options-what we can do here and now-are constrained by circumstances.

Constraints are external limitations on what a person who is not restrained can do that are intrinsic to their (external) circumstances. For example, the activities and options available to a person who has almost no money are subject to severe financial constraints. Whether a person who is able to swim and is not restrained can swim depends on the availability of a swimming pool at a cost s/he can afford. While it is possible to coerce a person by restraining them from doing an activity they can do, it is not possible to restrain them from doing something which they could only do if the circumstances were different.

Unless the person is subject to pre-existing restraints, establishing the level of restraint (coercion) in a particular situation involves establishing what the individual can do and wishes to do ('wills') but for any interference by another person with their freedom to do it. It is or should also be a 'but-for test'.

By way of example, say that the present circumstances are such that I am able to swim and a pool is open locally which I can both afford and access. I can go swimming if I wish to unless someone now interferes with my individual freedom to do what I am able to do and wish to do, in which case I am subject to coercion. However, if no pool is available to access then I cannot go swimming even though I wish to. Consequently, the possibility of someone interfering with my freedom to go swimming does not arise.

In our field of interest, this is again relevant when it comes to considering the position of a person with a physical or mental disability.

The decision in Cheshire West has been interpreted in practice as stating that a deprivation of liberty occurs whenever an incapacitated person is under another person's complete supervision and control and is not free to leave without reference to whether there is or has been any actual coercion or interference with the individual's freedom to do what they are able to do and choose to do. ${ }^{36}$ This is problematic.

In the case of someone in the final sad stages of dementia, confined to bed and so cognitively impaired as to be unable to form the idea of swallowing let alone mobilising, there is no coercion or interference at all with their ability to do the acts they will nor therefore with what they can do. Hopefully the opposite is true. We go to great lengths to try to ascertain their will and to enhance their ability to act: we seek to enable them. Such a person's actions are circumscribed by the ever-reducing inner circles of their own abilities rather than by external lines and limits on their freedom to act drawn and imposed by others. The boundaries exist within the person not without.

If we apply our 'but for' test and ask the question, 'What are the things this person can do and wishes to do ('wills') but has not done because we have interfered or are interfering with their freedom to do them?' the probable answer is nothing.

The individual's ability to act autonomously, to be self-directing, has been reduced not by restraints on their freedom imposed by others but by their own reduced abilities. The effect of their increasing dementia is that they are now incapable of doing many of the things which previously they were able to do. Although they may be

${ }^{36} P$ v Cheshire West and Chester Council and $P$ and $Q v$ Surrey County Council [2014] UKSC 19. 
wholly unable to self-care, and so be under our complete care and supervision, we are not interfering with, limiting or 'controlling' their liberty to do anything which they can do. Hopefully we supervise and control what others do to them or for them but at this stage their own actions are not being controlled by others.

Nevertheless, following the Cheshire West decision, the usual starting point is that the person would be restrained from leaving were they to try to leave the hospital or care home and this demonstrates that they are under the continuous supervision and control of staff and are not free to leave. Because they are unable to consent to this confinement they satisfy both the objective and subjective conditions for a deprivation of liberty.

The counter-argument would be that this formulation does not accurately convey the reality of the person's concrete situation. One might just as well say that a baby below walking age would be prevented from leaving if they tried to walk out of the hospital or that a patient who has just died would be prevented from leaving were they to be suddenly raised from the dead, so that it is tempting to call this the Lazarus argument. If the person in our example was able to swallow, mobilise, orientate themselves and form the idea of going home they would not have severe dementia. Wishing or deciding to leave fall into the category of things which the person is now incapable of doing and one cannot properly speak of being prevented by others from doing something which one is incapable of doing. Nor can anyone possibly restrain a person from doing something which they do not have the ability to do at present. Mere inability is not lack of freedom.

As concerns MIG, it is not clear that she was prevented from doing anything which she was able to do and wished to do. ${ }^{37}$ Although her carers would have prevented her from leaving home if she was able to decide to do so, it seems unlikely that she was able to decide that and in any case she was content and devoted to her foster mother. She had never attempted to leave home on her own and had never shown a wish to do so. Likewise, although her foster mother would, it is said, have prevented her from mixing with unsuitable people there is no evidence that her level of social functioning enabled her to form relationships and make social choices with which her foster mother might need to interfere. She communicated with difficulty, 'indeed hardly at all in sentences' and had 'limited understanding'. She lived 'largely in her own world and spent 'much of her time listening to music on her iPod'. If we apply our 'but for' test, there seems to be little evidence that her concrete situation was that other persons were preventing her from doing what she was able to do and could do but for their restraint to a degree that might be said to amount to deprivation of liberty.

The situation was, of course, very different in HL. Other people did prevent him from doing what he was able to do and could do but for their restraint. He was physically restrained and sedated to keep him 'tractable' and stop him harming himself or others, and he was prevented from seeing his carers. In Storck, ${ }^{38}$ the applicant tried to

\footnotetext{
${ }^{37}$ Although Lady Hale refers to MIG's foster mother as being able to prevent MIG from leaving, and having power to restrict social contacts, there seems to be no or little reported evidence of this actually happening. See Lord Justice Wilson's judgment in the Court of Appeal for details of MIG's daily arrangements and activities: P \& Q v Surrey County Council [2011] EWCA Civ 190, [2011] 2 FLR 583.

${ }^{38}$ Storck v Germany, no. 61603/00, 16 June 2005, ECHR 2005-V, 43 EHRR 96, [2005] ECHR 406.
} 
flee from the clinic on several occasions. In Shtukaturov, ${ }^{39}$ the applicant attempted to flee the hospital, was tied to his bed, given an increased dose of sedative medication and prevented from communicating with the outside world. In DD v Lithuania, ${ }^{40}$ the applicant left the institution without informing its management, only to be brought back by the police, and who he could see, and speak with, was controlled. In $\mathrm{Mi}$ hailovs, ${ }^{41}$ the applicant applied to be released and could not leave the institution without its management's permission. If we apply our 'but for' test to each of these cases and ask the question, 'What are the things this applicant can do and wishes to do ('wills') but has not done because we have interfered or are interfering with their freedom?' the concrete case is that the restraint was significant.

It should be emphasised that our 'but for' test is quite different to the 'normal life', 'most normal life possible' and 'relative normality' tests invoked by the High Court and the Court of Appeal at earlier stages of the Cheshire West appeals process.

The fact that a person is living a relatively normal life when compared with other citizens will often indicate that they are subject to little or no restraint; however, the test must be whether and to what extent their liberty is restrained, not how relatively normal their life is because the latter also depends on the extent to which they have the capacity for autonomous action.

Similarly, contrasting the person's life with the 'normal life' led by an adult of similar age with the same capabilities, affected by the same condition or suffering the same inherent mental and physical disabilities and limitations, ${ }^{42}$ cannot be the correct approach. The 'normal life' of an adult with the same capabilities, condition and inherent mental limitations may be confinement in a high secure hospital if the condition in question is a severe 'psychopathic disorder' associated with homicidal violence, sexual offending and criminal conduct. Likewise, the 'normal life' of someone with a very profound learning disability may include frequent displays of aggressive or self-injurious conduct that require 3:1 supervision and the exercise by others of considerable restraint. Yet no one could reasonably argue that either person is not deprived of their liberty.

Lady Hale's always commendable compassion was evident in Cheshire West when she concluded by saying that because 'of the extreme vulnerability of people like $\mathrm{P}$, MIG and MEG, I believe that we should err on the side of caution in deciding what constitutes a deprivation of liberty in their case. They need a periodic independent check on whether the arrangements made for them are in their best interests ...,43

Few if any would argue that people in MIG's position need a periodic independent check on whether the arrangements made for them are in their best interests. However, in many cases, probably including MIG's, the need for strict legal safeguards arises not from loss of liberty but from a loss of autonomy that leaves the person

\footnotetext{
${ }^{39}$ Shtukaturov v Russia, no. 44009/05, 27 March 2008, 54 EHRR 962.

${ }^{40}$ DD v Lithuania, no. 13469/06, 14 February 2012, [2012] ECHR 254.

${ }^{41}$ Mihailovs v Latvia, no. 35939/10, 22 January 2013, [2013] ECHR 65.

${ }^{42}$ See the decision of Munby P. in Cheshire West \& Chester Council v P (by the OS) CA [2011] EWCA Civ 1257, 9 November 2011.

${ }^{43} P v$ Cheshire West and Chester Council and $P$ and $Q v$ Surrey County Council [2014] UKSC 19, at para. 57.
} 
wholly dependent on and at the mercy of others, and so wholly vulnerable to abuse and inadequate care. If that is correct, imposing on the relevant hospital, care home, family and carers legal proceedings and procedures designed to protect individuals from unwarranted deprivations of liberty is not the most appropriate response.

The need here is to ensure that each country has mechanisms in place for regularly visiting and checking on the welfare of vulnerable, incapacitated citizens. These visiting schemes need to be supported by a legally-led Mental Health Law and Welfare Commission independent of government which can investigate complaints and cases of concern and ensure compliance with mental health and incapacity legislation.

If this goes slightly further than the European Court of Human Rights presently requires it is nevertheless a logical extension of the protective measures already required of member states. The court has already emphasised in several judgments under Articles 2, 3 and 8 that there is a duty on states to ensure that hospitals adopt appropriate measures to protect patients' lives' $; 4$ to adopt appropriate measures with regard to vulnerable prisoners at risk of suicide; ${ }^{45}$ to take positive measures to protect the physical and mental health of patients in a position of inferiority and helplessness; ${ }^{46}$ and to secure the right to effective respect for physical, moral and psychological integrity. 47

The final stage in distinguishing between autonomy and liberty is to consider how they may be affected by external constraints.

The external world may be adjusted to allow equal opportunities to people with a particular disability or it may not. For example, there may or may not be an accessible transport system for people who cannot mobilise independently without one.

Unless their world is perfectly adjusted, the activities and opportunities available to a person who is only able to mobilise with assistance - 'what they can do' - will be more constrained by external circumstances than those of a person who is able to mobilise independently.

If fewer opportunities are available to a person who requires assistance in order to mobilise, in everyday conversation we may loosely say that there are fewer things they are 'free to' do. However, the person has not been deprived of any freedom by others. They are 'free from' any interference with their freedom to do what they can do. Coercion implies the deliberate interference of other human beings within the area an individual would otherwise act ${ }^{48}$ and the freedom of someone who is not

\footnotetext{
${ }^{44}$ Calvelli and Ciglio v Italy, judgment (Grand Chamber) of 17 January 2002, §49.

${ }^{45}$ Ketreb v France, no. 38447/09, 19 July 2012.

${ }^{46}$ See e.g. Herczegfalvy v Austria, no. 10533/83, Series A no. 244, [1992] ECHR 58, (1992) 15 EHRR 437 (the 'Herczegfalvy case').

${ }^{47}$ Sentges v Netherlands (dec), no. 27677/02, 8 July 2003; Pentiacova and Others v Moldova (dec) no. 14462/03, 4 January 2005; Nitecki v Poland (dec), no. 65653/01, 21 March 2002.
}

${ }^{48}$ Mill [6], p. 135. Mill was of the opinion that the 'only purpose for which power can rightfully be exercised over any member of a civilized community, against his will, is to prevent harm to others. His own good, either physical or moral, is not a sufficient warrant... Over himself, over his own body and mind, the individual is sovereign.' This passage, often quoted in articles on mental health legislation, seems most often to have been read from a secondary source because reference is rarely made to the qualification which forms the first sentence of the very next paragraph: 'It is, perhaps, hardly necessary to say that this doctrine is meant to apply only to human beings in the maturity of their faculties... Those who are still 
subject to pre-existing restraints is only restricted to the extent that another person restrains them from doing something they can do.

This may sound unsympathetic. It is not meant to be. It simply acknowledges that we must be careful not to conflate different principles, in this case liberty and equality of opportunity. It is true that many people have few choices to choose freely between. A person may be free from any restriction on their liberty to learn but have no opportunity to learn. However, a lack of opportunity is exactly that, a lack of opportunity not coercion. It is a constraint.

Although unequal resources and opportunities do not reduce our liberty they do impact on our autonomy. This occurs when the consequence is that we depend on others for assistance to perform an activity which we are capable of performing independently, and it is why disability and equality laws are so important.

How then can we increase the autonomy of a person who is subject to constraints because they are disabled by a mental or physical impairment? You have two options: to change the person or to change the world.

This is easily illustrated. Imagine two fixed spheres of equal size that overlap so as to give an appearance like the eclipse of the sun. The left sphere comprises all of the person's abilities and the right sphere the opportunities available to them in their external world. The overlap represents what they can do because within it is are all the activities which they are able to do and are also available to them to do (their present circumstances or options). We can increase the area of overlap either by expanding their sphere of abilities or by expanding their sphere of opportunities (which is simply another way of saying by reducing the constraints to which they are subject).

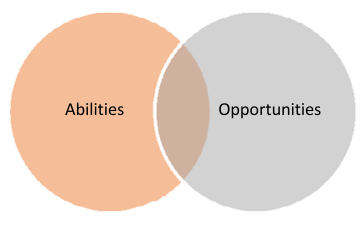

Pre-existing situation

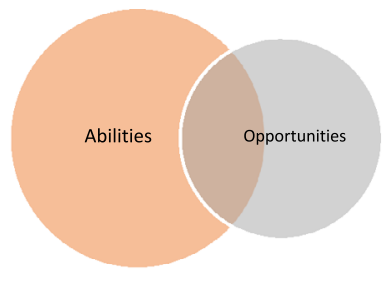

Increase abilities, e.g. by providing an aid

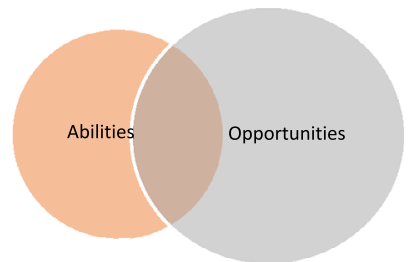

Reduce constraints, e.g. by adapting environment

Using the previous example of a person who acquires an aid in the form of a wheelchair and is now able to mobilise independently, in diagrammatic form what has happened is that the person's circle of abilities, and in particular what they are able to do independently, has increased with the result that there are now more things they can do autonomously in the external world. However, there has been no change in their freedom and no change in the external world. They simply have more autonomy because they are now able to do more of the things they are capable of.

It is also possible to increase the activities a person can undertake independently without any change in their individual abilities: The area where a person's abilities

in a state to require being taken care of by others, must be protected against their own actions as well as against external injury.' 
and the opportunities to exercise them overlap can be increased by increasing the circle of opportunities and activities available in the external world to people with their current circle of abilities. The practical effect is similar.

A simple example is that of a person in a wheelchair who cannot use the washroom facilities at work independently because they are at the wrong height. If the facilities are adapted their autonomy increases. It increases because the external world around them is now constructed to enable someone with their abilities to be independent in this respect. Although what they can do autonomously has increased there has been no increase in their individual abilities or in their freedom. They are just as free as before to do all the things they can do.

These examples illustrate the difference between aids and adaptations, disabilities and handicaps, autonomy and freedom. An aid such as a replacement knee or wheelchair is designed to enable the individual. There is a change in their individual abilities. Although the external world is unchanged, they are now able to perform activities in the external world which previously they were unable to perform. They are more 'enabled' and less 'disabled'. An adaptation is a modification of the external world. An environment such as a kitchen, building, outside space or transport system may be adapted or not adapted to provide equal access or opportunities for people with different abilities and needs. If an environment is suitably adapted a disabled person can do more activities independently without any increase in their range of abilities. They are more autonomous.

All of this is consistent with, and so supported by, the World Health Organisation's elegant International Classification of Impairments, Disabilities and Handicaps which uses the three concepts in the classification title to describe the consequences of disease or injury: ${ }^{49}$

Disease or injury The individual develops some intrinsic abnormality which may be described as a disease or an injury and have been present at birth or acquired later. It may or may not cause an impairment.

Impairment An impairment is a permanent or temporary loss or abnormality of bodily structure or function. It represents the occurrence of an anomaly, defect or loss in a limb, organ or tissue or the defective functioning of part of the body, including the systems of mental function.

Disability The fact that part of the body is impaired may or may not affect the individual's ability to perform different activities - if so, the impairment has a disabling effect. A disability is a restriction or lack of ability to perform an activity in the manner or within the range considered normal for a human being. Disabilities may be temporary or permanent, reversible or irreversible, progressive or regressive. By focusing on activities, the idea of disability is concerned with the practical consequences of bodily impairment in a relatively neutral way.

${ }^{49}$ World Health Organisation [10], pp. 10-11. 
Handicap

The word 'handicap' describes the disadvantages resulting from impairment and disability which limit or prevent fulfilling a role that is normal for that person. As in horse racing, the state of being handicapped is relative to others. The degree of handicap experienced will depend on the individual's situation, the support available and the attitudes of others. Because of the stigma attached to mental illness and compulsory treatment, a detained patient who has recovered may still be handicapped. For example, a person once diagnosed as having schizophrenia will be at a serious disadvantage when it comes to competing with others for employment, even if the diagnosis was erroneous or they have subsequently fully recovered. Although the individual is no longer impaired or disabled they are handicapped.

All three concepts depend on deviations from norms ${ }^{50}$ and the sequence underlying illness-related phenomena is presented as follows: ${ }^{51}$

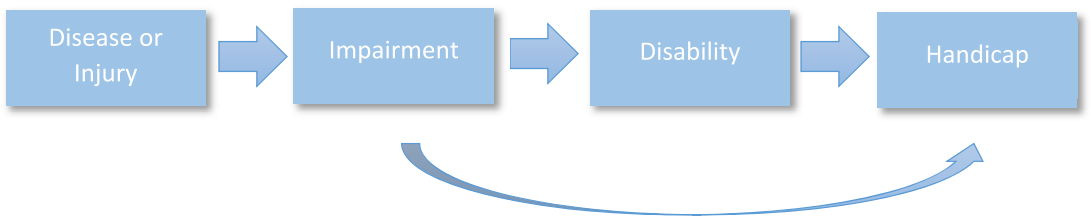

This sequence of events may be interrupted at any stage: an impaired person may never become disabled and, likewise, a disabled person may not become handicapped. The value of presenting the concepts in this way is that 'a problem-solving sequence is portrayed, intervention at the level of one element having the potential to modify succeeding elements. ${ }^{52}$

From this and the foregoing analysis it can be seen that there are five ways in which an individual's autonomy may be maximised. Firstly, by turning capabilities into abilities, for example by the provision of an aid. Secondly, in the case of progressive disabling illnesses such as dementia, by finding ways of slowing the rate at which they become incapable of performing activities autonomously. Thirdly, by reducing the constraints ('handicaps') which impact on persons with disabilities and prevent them from acting autonomously, e.g. by adapting the external world so that people with a range of human abilities can engage in more activities autonomously. Fourthly, by reducing pre-existing restrictions; for example, by reducing the number of people subject to mental health legislation. Fifthly, in the case of people not subject to pre-existing restraints, by not interfering or interfering less with their freedom to do what they can and wish to do.

\footnotetext{
${ }^{50}$ World Health Organisation [10], p. 33.

${ }^{51}$ World Health Organisation [10], pp. 11, 25-27.

${ }^{52}$ World Health Organisation [10], p. 30.
} 


\section{Concluding remarks}

All human rights decision-making has a policy element. Because the different approaches taken by both the European Court of Human Rights and the Supreme Court have clear benefits, it is tempting to try to combine them.

The best fit, in terms of protecting the liberty of mentally incapacitated people whilst not interfering unduly in the lives of incapacitated people who are being cared for in accordance with their wishes and feelings is to focus on the objective condition, and in particular the intensity of any supervision and control to which they are subject and any impact this has on their liberty.

Focusing on the objective condition enables the court to take into account and give weight to the individual's wishes and feelings - and in particular whether they are content and agree with or object to the residential care arrangements made for themwithout compromising the subjective condition by watering down the requirement that all objective confinements are a deprivation of liberty unless the confined person has legal capacity to consent to their confinement and does consent.

If a person is so incapacitated that decisions about where they are to live and what care and treatment they are to receive must be made by others, rather than by them with the support of others, it cannot be said that they have given a valid consent to any confinement which then exists. Therefore, a deprivation of liberty will exist if the objective condition is satisfied.

Where domestic laws permit a guardian to give a valid legal consent to care arrangements which objectively involve confining a person who in law lacks capacity to make the decision for themselves, the guardian's vicarious legal consent does not affect the fact that such a confinement is a deprivation of liberty for Article 5 purposes. To hold otherwise would create a situation whereby vulnerable people who lack capacity can be objectively confined without the benefit of the protections afforded by Article 5, and in particular the right of access to a court.

With regard to the objective condition, the Storck test could usefully be rephrased so that what is required is that the relevant person 'is under continuous supervision and control and is unable to leave'. This is because 'unable to leave' includes both those who are prevented from leaving and those who are unable to leave because of lack of capacity.

If an incapacitated person is unable to leave it is artificial to ask whether they are free to leave or would be prevented from leaving if they were to attempt to leave. For a person in that situation the critical issue-and indeed the only live issue if the subjective condition (no valid consent) is satisfied and they are unable to leave-is the intensity of the care regime and how it impacts on their liberty. As is well-known, the starting-point here is the concrete situation of the individual concerned and account must be taken of a whole range of factors such as the type, duration, effects and manner of implementation of the measures in question.

When assessing the individual's concrete situation and the effect of the measures in force, it is important to distinguish carefully between loss of autonomy and loss of liberty. Unless a person is subject to pre-existing restraints, establishing the level of restraint in a particular situation involves establishing what the individual can do and wishes to do ('wills') but for any interference by another person with their freedom to do it. It is or should also be a 'but-for test'. 
It is also critical to understand that the objective and subjective conditions overlap so that the presence or absence of coercion, the person's wishes and feelings, the existence of objections, and the absence of objections from someone capable of objecting, are always relevant to the objective condition, not just the subjective condition. All of these things help us to establish the breath and intensity of any supervision and control and also whether or not the person is being prevented from doing what they can do and wish to do.

If we give weight to these factors and apply a 'but for' test to the well-known cases referred to in this article, and other well-known cases, the outcomes are almost identical but one is spared the ambiguities associated with the subjective condition:

MIG Not deprived of liberty. Applying Eldergill but-for test, little evidence that her concrete situation was that other persons were preventing her from doing what she was able to do and wished to do 'but for' their restraint to a degree that might be said to amount to deprivation of liberty. Intensity of supervision and control insufficient. Her wishes and feelings could be implied from her devotion to her foster mother and the absence of any need for restraint or sedating medication. Likely that she was content and had no objection to express, by words or behaviour.

HL Deprived of liberty. Prevented by others from doing what he was able to do and could do but for their restraint. Physically restrained and sedated to keep him 'tractable' and stop him harming himself or others. Prevented from seeing his carers in case he wanted to leave with them.

Storck Deprived of liberty. Tried to flee from the clinic on several occasions. But for this restraint he would have left.

Shtukaturov Deprived of liberty. Attempted to flee the hospital, was tied to his bed, given an increased dose of sedative medication and prevented from communicating with the outside world.

DD Deprived of liberty. Left the institution without informing its management, only to be brought back by the police. Who he could see and speak with was controlled by others.

Mihailovs Deprived of liberty. Applied to be released and therefore clearly objected. Could not leave the institution without its management's permission.

$H M^{53} \quad$ Not deprived of liberty. After her arrival at the nursing home, she agreed to stay. 'Had freedom of movement and was able to maintain social contact with the outside world'. She was 'hardly aware of the effects of her stay in the nursing home'.

Nielsen ${ }^{54} \quad$ Not deprived of liberty. His treatment 'did not involve medication, but consisted of regular talks and environmental therapy'. The restrictions to which he was subject were no more than the normal requirements for the care of a child of 12 years of age receiving treatment in any hospital and were not of a level sufficient to constitute a deprivation of liberty. 
People with Not deprived of liberty if the answer to Eldergill 'but for' test- 'What dementia in are the things this person can do and wishes to do ('wills') but has not care homes done because we have interfered or are interfering with their freedom to do them?'-is nothing or so little as to be insufficient to cross the restriction of liberty/deprivation of liberty threshold. Depends on whether the person objects to their placement or is restrained, e.g. prevented from leaving or going out, sedated, physically restrained.

Although not all of these individuals were found to have been deprived of their liberty, all of them were vulnerable. The need for strict legal safeguards in some cases arises not from loss of liberty but from a loss of autonomy that leaves the person wholly dependent on and at the mercy of others, and so wholly vulnerable to abuse and inadequate care. Each country should have mechanisms in place for regularly visiting and checking on the welfare of vulnerable, incapacitated citizens.

Open Access This article is distributed under the terms of the Creative Commons Attribution 4.0 International License (http://creativecommons.org/licenses/by/4.0/), which permits unrestricted use, distribution, and reproduction in any medium, provided you give appropriate credit to the original author(s) and the source, provide a link to the Creative Commons license, and indicate if changes were made.

\section{References}

1. Berlin, I.: Four Essays on Liberty. Oxford University Press, Oxford (1969)

2. Bodkin, R.C.: How to Reason, 3rd edn. Browne \& Nolan Ltd., Dublin (1906)

3. Eldergill, A.: Mental Health Review Tribunals: Law and Practice. Sweet \& Maxwell, London (1997)

4. Hobbes, T.: Leviathan. Global Grey Books, London (2015)

5. Locke, J.: An Essay Concerning Human Understanding, Bk. III. Clarendon, Oxford (1975)

6. Mill, J.S.: On Liberty. Collins, Glasgow (1962)

7. Popper, K.: Conversation with Karl Popper. In: Magee, B. (ed.) Modern British Philosophers. Paladin, London (1973)

8. Roth, M.: Psychiatric diagnosis in clinical and scientific settings. In: Akiskal, H.S., Webb, W.L. (eds.) Psychiatric Diagnosis: Exploration of Biological Predictors. S.P. Medical \& Scientific Books, New York (1978)

9. Whitney, W.D. (ed.): The Century Dictionary and Cyclopedia: An Encyclopedic Lexicon of the English Language, vol. 1 A-CELT. The Century Co., New York (1904)

10. World Health Organisation: International Classification of Impairments, Disabilities, and Handicaps, A manual of classification relating to the consequences of disease (1976)

\footnotetext{
${ }^{53}$ HM v Switzerland, no. 39187/98, 26 February 2002, ECHR 2002-II, [2002] ECHR 157, (2002) 38 EHRR 314.

${ }^{54}$ Nielsen v Denmark, no. 10929/84, 28 November 1988, Series A no. 144, [1988] ECHR 23, (1988) 11 EHRR 175.
} 